\title{
Tingkat Aksesibilitas Pelayanan Air bagi Masyarakat di Kawasan Padat Penduduk
}

\author{
Dhyah Puspita Dewi*1 $^{1}$, adjar Hari Mardiansjah ${ }^{2}$ \\ ${ }^{1}$ Magister Pembangunan Wilayah dan Kota, Departemen Perencanaan Wilayah dan Kota, \\ Fakultas Teknik Universitas Diponegoro, Semarang Indonesia \\ ${ }^{2}$ Departemen Perencanaan Wilayah dan Kota, \\ Fakultas Teknik Universitas Diponegoro, Semarang Indonesia \\ Email: 1dhyahpuspitadewi@gmail.com
}

Received 09 Desember 2019; Reviewed 27 April 2020; Accepted 06 Juni 2020

Journal Homepage: http://jurnal.borneo.ac.id/index.php/borneoengineering

DOI: https://doi.org/10.35334/be.v4i1.1103

\begin{abstract}
The existence of government programs and the existence of a government corporation appointed by the government to provide water to the community is still not enough to meet the needs of clean water. Areas that have been served are still experiencing water access problems. Areas that have not adapted to use other sources using ground water for personal needs or for business, however, it cannot be used forever, so someday they have to switch to water sources provided by the government. On the other hand, lower middle income communities are vulnerable to access to water, which concentrated in densely populated and coastal areas, which is difficult for the government to provide access to water services. Therefore, this study wants to show access to water services provided by the government and ground water supply providers, and how access is received by each community group. The location of this study is in Kemijen Village which majority consists of the customers of water sources provided by the government and Kampung Tambak Lorok which majority consists of customers of ground water sources. The results show that groundwater providers provide better access, where lower middle class people get lower access than upper middle class people.
\end{abstract}

Keywords: access to water services, densely populated urban areas, lower middle income communities

\begin{abstract}
Abstrak
Adanya program pemerintah dan hingga adanya badan yang ditunjuk oleh pemerintah untuk menyediakan air bagi masyarakat masih belum cukup untuk memenuhi kebutuhan air bersih. Daerah yang telah terlayani pun masih mengalami masalah akses air. Wilayah yang belum teraliri beradaptasi dengan menggunakan sumber lain, salah satunya adalah dengan menggunakan air tanah, yang digunakan untuk kebutuhan pribadi maupun dijual kepada pelanggannya, Akan tetapi, sumber air tanah belum tentu bisa digunakan selamanya, sehingga mereka suatu saat harus beralih ke sumber air yang disediakan pemerintah. Di sisi lain, masyarakat menengah ke bawah rentan akan akses air, karena terkonsentrasi di kawasan yang padat penduduk dan pesisir, dimana sulit bagi pemerintah untuk memberikan akses pelayanan air. Oleh karena itu, penelitian ini ingin menunjukkan akses pelayanan air yang disediakan oleh pemerintah dan penyedia sumber air tanah, dan bagaimana akses yang diterima oleh masing-masing kelompok masyarakat. Lokasi penelitian ini berada di Kelurahan Kemijen dengan mayoritas pelanggan merupakan pelanggan sumber air yang disediakan oleh pemerintah dan Kampung Tambak Lorok dengan mayoritas pelanggan merupakan pelanggan penyedia sumber air tanah. Hasil penelitian menunjukkan bahwa penyedia air tanah memberikan akses lebih baik, di mana masyarakat menengah ke bawah mendapatkan akses yang lebih rendah daripada masyarakat menengah ke atas.
\end{abstract}

Kata kunci: akses pelayanan air, kawasan padat penduduk perkotaan, masyarakat menengah ke bawah 


\section{Pendahuluan}

Kebutuhan air untuk masyarakat dunia semakin meningkat namun tidak dibarengi dengan ketersediaan air. Watkins (2006) menyebutkan, saat ini 700 juta penduduk di 43 negara hidup dengan kelangkaan air. Kelangkaan air memaksa penduduk di dunia untuk menggunakan air yang tidak aman untuk diminum dan untuk penggunaan domestik lainnya (WHO, 2007). Selain itu, penduduk dunia juga membutuhkan air yang mampu mengalir sepanjang hari, sehingga selalu tersedia air kapanpun ketika dibutuhkan. Di Indonesia, di musim tertentu, sudah menjadi kelaziman bahwa di tiap kota memiliki spot tertentu yang mengalami kelangkaan air. Dalam Forum Air Dunia II (World Water Forum) di Den Haag disebutkan bahwa Indonesia termasuk ke dalam negara yang akan mengalami krisis air pada tahun 2025.

Pemerintah telah berupaya dalam berbagai hal. Selain melalui berbagai program seperti 100-10-100 sebagai perpanjangan tangan dari kesepakatan dalam Sustainable Development Goals (SDGs), pemerintah melalui melalui Perusahaan Daerah Air Minum (PDAM) berusaha menyediakan air di tiap wilayah yang dinaunginya. PDAM dibutuhkan masyarakat perkotaan untuk mencukupi kebutuhan air bersih yang layak dikonsumsi, karena air tanah di perkotaan pada umumnya telah tercemar, dan di sisi lain penggunaan air tanah secara berlebihan telah menurunkan permukaan air tanah dan intrusi air laut, yang mengakibatkan menurunnya kualitas air tanah (Suhartono, Suripin, \& Purwanto, 2013). Sayangnya, masih banyak ditemukan daerah yang belum teraliri air bersih. Pada Tahun 2016, tercatat saluran PDAM Tirta Moedal baru mencakup 60\% (Setiawan, 2016). Akan tetapi, daerah yang teraliri pun bukan berarti tidak mempunyai masalah. Masih ada kawasan yang tidak merasakan air yang dapat diakses kapanpun ketika dibutuhkan, terutama di waktu ketika pemakaian air sangat tinggi (jam sibuk).

Kawasan yang belum teraliri PDAM menggunakan sumber air lain dan umumnya adalah air tanah yang pada peruntukannya untuk digunakan sendiri maupun dijualbelikan kepada pelanggannya. Akan tetapi, keberlanjutan sumber air tanah tidak dapat digunakan selamanya, sehingga suatu saat mereka harus berpindah ke sumber air yang disediakan oleh pemerintah. Di sisi lain, penggunaan sumber air tanah yang masif berpengaruh besar dalam menurunkan permukaan tanah. Elevasi di Kelurahan Kemijen dan Kampung Tambak Lorok antara 0,75 - 2,45 m di atas permukaan laut. Maka, ada bagian kawasan yang kurang 1 meter di atas permukaan laut. Kemudian, level penurunan tanah di lokasi studi bervariasi yaitu 3-6 cm/tahun dan 9-13 cm/tahun yang semakin membuat daerah rentan terhadap rob dan banjir.

Masyarakat menengah ke bawah menjadi bagian yang kesulitan mengakses, terlebih bila bukan menggunakan sumber air bersih dari pemerintah sejak awal. Masyarakat ini seringkali terkonsentrasi di kawasan pesisir dimana air tanah seringkali telah berubah rasa menjadi asin akibat intrusi air dan di kawasan padat penduduk di mana air tanah dianggap sudah mulai tercemar, sumber air tersebut menjadi kurang nyaman untuk dikonsumsi. Maka, perlu ada peran pemerintah untuk turut menyalurkan air ke kawasan tersebut.

Penyediaan air bersih yang ada dalam suatu permukiman harus dapat diakses oleh semua penghuninya. Aksesibilitas adalah mengenai kemudahan untuk mendapatkan akses sehingga bisa digunakan untuk beraktivitas dengan nyaman (Widyonarso \& Yuliastuti, 2014). Aksesibilitas air bersih penduduk suatu permukiman dapat dilihat dari jarak untuk mendapatkan air dan waktu yang dibutuuhkan untuk mengumpulkan air (Howard \& Bartram, 2003). Namun berbeda dengan pandangan Hofmann, P (2004 dalam Allen \& Dávila, 2006) bahwa kelayakan akses pelayanan air 
tidak terlalu bergantung kepada jarak ke sumber air dan jumlah penduduk yang menggunakan fasilitas yang sama, namun juga berkaitan dengan jumlah atribut pelayanan seperti peraturan, efisiensi, keterjangkauan, kualitas dan keamanan.

Air bersih dalam kehidupan manusia merupakan salah satu kebutuhan paling esensial, sehingga kita perlu memenuhinya dalam jumlah dan kualitas yang memadai. Selain untuk dikonsumsi air bersih juga dapat dijadikan sebagai salah satu sarana dalam meningkatkan kesejahteraan hidup melalui upaya peningkatan derajat kesehatan (Sutrisno, 1991:1). Penyediaan air bersih dengan kualitas yang buruk akan mengakibatkan dampak yang buruk juga untuk kesehatan sehinngga kualitas air bersih harus terkontrol dan terjamin. Penyediaan air bersih harus dapat melayani sebagian besar/ seluruh masyarakat, agar masyarakat yang terkena penyakit yang berkenaan dengan air dapat diturunkan.

Hal ini tidak dapat hanya dilakukan oleh pemerintah sebagai pelayan masyarakat melainkan semua pihak termasuk masyarakat itu sendiri untuk mengetahui pentingnya hidup sehat dengan salah satunya menggunakan air bersih. Di Indonesia ketentuan mengenai standar kualitas air bersih mengacu kepada Peraturan Menteri Kesehatan Nomor: 416 tahun 1990 tanggal 3 September 1990 tentang syarat-syarat dan pengawasan kualitas air. Dalam peraturan tersebut standar air bersih dapat dibedakan menjadi empat ketegori, yaitu persyaratan kualitas air untuk air minum, persyaratan kualitas air untuk air bersih, persyaratan kualitas air untuk air kolam renang, dan persyaratan kualitas air untuk air pemandian umum.

Berdasarkan uraian di atas, maka aksesibilitas penduduk terhadap penyediaan air bersih dilihat dari jarak, waktu untuk menjangkau dan mengumpulkan air, serta kualitas air bersih. Akan tetapi berbagai kriteria di atas tidak seluruhnya sesuai apabila diterapkan di lingkungan padat penduduk seperti di lokasi studi. (1) Sumber air yang digunakan diprediksikan tidak hanya menggunakan sumber air perpipaan berupa air PDAM dan artetis saja, melainkan juga setidaknya menggunakan air kemasan dan air isi ulang. (2) Jarak yang digunakan kemungkinan menjadi tidak relevan karena kemungkinan besar penduduk telah menggunakan sumber air perpipaan di tiap rumah. Oleh karena itu, keberadaan jarak akan digunakan dengan cara menghitung jarak rumah dengan sumber utama, yaitu pipa utama untuk yang bersumberkan PDAM dan tower artesis bagi yang bersumberkan artesis. (3) Kemudian, ada kemungkinan perbedaan konteks mengenai waktu untuk menjangkau air. Pada penelitian ini, waktu akan diperluas sehingga tidak hanya mengenai waktu menjangkau air, namun juga melihat bagaimana frekuensi air yang mengalir dalam seminggu dan berapa lama waktu air mengalir dalam satu hari, dan bagaimana derasnya air. Oleh karena konteksnya diperluas, penulis menerjemahkannya sebagai kehandalan. Berdasarkan ketiga hal tersebut, maka perlu dibuat standar analisa baru yang sesuai dengan hasil penelitian di lokasi studi.

Oleh karena itu, paper ini ingin menunjukkan seberapa tinggi tingkat aksesibilitas pelayanan air yang diberikan oleh masing-masing penyedia, yang diterima oleh masing kelompok masyarakat, dan bagaimana keseluruhannya bila dilihat secara generalisir.

\section{Lokasi, Metode Penelitian, dan Metode Pengumpulan Data}

Penelitian ini berada di kawasan padat penduduk di Kota Semarang, yaitu di Kampung Tambak Lorok dan Kelurahan Kemijen. Kedua kawasan tersebut memiliki perbedaan sumber air yang digunakan, yaitu sumber air yang dikelola oleh pemerintah atau PDAM yang terkonsentrasi di Kelurahan Kemijen dan sumber air yang dikelola oleh swasta dalam skala rumah yaitu artesis yang terkonsentrasi di Kampung Tambak Lorok, sehingga diharapkan mendapatkan jawaban yang lebih 
jelas mengenai bagaimana akses pelayanan air yang didapatkan oleh masyarakat. Selain itu, lokasi ini juga memiliki jumlah penduduk menengah ke bawah yang tinggi. Jumlah penduduk miskin di Kampung Tambak Lorok adalah 1,557 KK atau 36,01\% dari total jumlah penduduknya, sehingga jumlah penduduk non miskinnya adalah 2,767 KK atau 63,99\%. Jumlah penduduk miskin Kelurahan Kemijen adalah 1,371 KK atau 41,57\% dari total jumlah penduduknya, sehingga jumlah penduduk non miskinnya adalah $1,927 \mathrm{KK}$ atau $58,43 \%$.

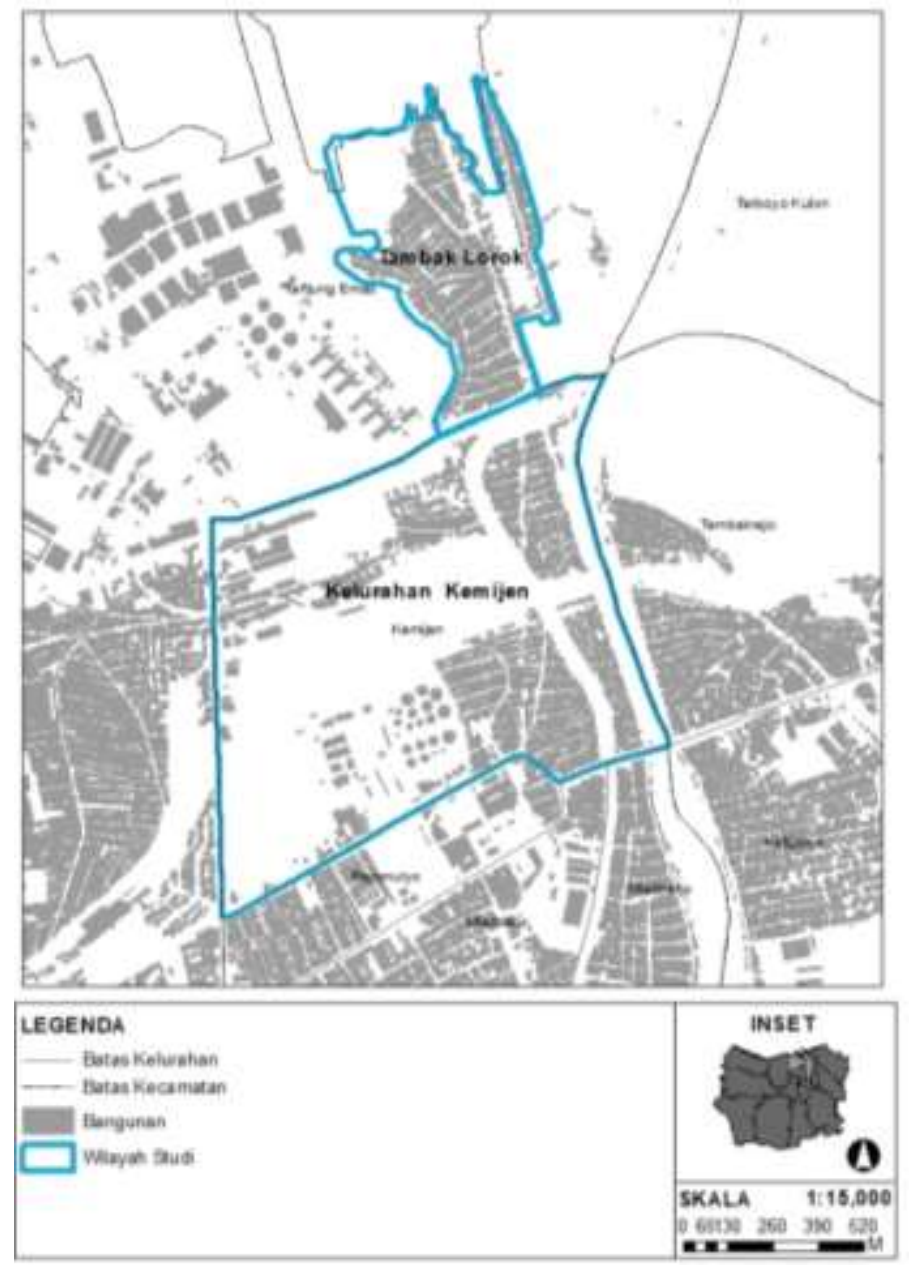

Gambar 1. Lokasi Area Penelitian

Penelitian ini mengumpulkan setiap jawaban responden yang kemudian diterjemahkan dalam bentuk skor tertentu yang kemudian memberikan nilai yang menunjukkan bagaimana akses pelayanan air yang didapatkan. Teknik sampling yang digunakan untuk kuesioner dalam penelitian ini mengggunakan teknik probability sampling yaitu proportionate stratified random sampling. Proportionate stratified random sampling merupakan teknik yang digunakan untuk menentukan sampel, bila populasi mempunyai anggota/unsur yang tidak homogen dan berstrata secara proporsional (Sugiyono, 2012). Oleh karena penelitian ini menyasar kepada rumah tangga, maka perhitungan sampel dilakukan berdasarkan jumlah kepala keluarga (KK). Jumlah kepala keluarga di Kampung Tambak Lorok adalah 3,346 KK sedangkan jumlah kepala keluarga di Kelurahan Kemijen adalah 2,216 KK, maka jumlah populasi adalah 5,562 KK. Apabila jumlah sampel ditentukan menggunakan rumus Slovin, maka jumlah sampel penelitian ini adalah sebagai berikut: 


$$
n=\frac{\mathrm{N}}{\mathrm{Nd}^{2}+1}=\frac{5,562}{5,562 \times 0,1^{2}+1}=98.339=98 \text { sampel }
$$

Keterangan:

$$
\begin{array}{ll}
\mathrm{n} & =\text { Jumlah Sampel } \\
\mathrm{N} & =\text { Jumlah Populasi } \\
\mathrm{d} & =\text { Derajat Kecermatan (Level of Significance) }
\end{array}
$$

Oleh karena jumlah sampelnya berstrata, maka sampelnya juga berstrata. Rumusnya ialah sebagai berikut:

Keterangan:

$$
n i=\frac{N i * n}{N}
$$

$\mathrm{n} \quad=$ Jumlah sampel

ni $\quad=$ Jumlah sampel wilayah ke $\mathrm{i}$

$\mathrm{N} \quad=$ Jumlah populasi

$\mathrm{Ni}=$ Jumlah populasi wilayah ke $\mathrm{i}$

Maka jumlah sampel tiap wilayah studi adalah sebagai berikut:

Tabel 1. Tabel Lokasi Penelitian Dan Jumlah Sampel

\begin{tabular}{lc}
\hline Lokasi Penelitian & Jumlah Sampel Penduduk \\
\hline Kampung Tambak Lorok & 39 \\
Kelurahan Kemijen & 59 \\
\hline
\end{tabular}

Analisa aksesibilitas dilakukan dengan menggabungkan variabel aksesibilitas air yaitu jarak (jarak rumah ke sumber air perpipaan yaitu pipa utama bagi pelanggan PDAM dan tower artesis bagi pelanggan artesis), kuantitas penggunaan air, kehandalan (frekuensi air yang mengalir dalam

\begin{tabular}{|c|c|c|c|}
\hline No & Variabel & Indikator & Nilai \\
\hline \multirow[t]{5}{*}{1} & Jarak & $>400 \mathrm{~m}$ & 1 \\
\hline & & $300-400 \mathrm{~m}$ & 2 \\
\hline & & $201-300 \mathrm{~m}$ & 3 \\
\hline & & $101-200 \mathrm{~m}$ & 4 \\
\hline & & $0-100 \mathrm{~m}$ & 5 \\
\hline \multirow[t]{15}{*}{2} & Frekuensi & & \\
\hline & Frekuensi mingguan & Mengalir $<4$ hari seminggu & 1 \\
\hline & & Mengalir 4 hari semingu & 2 \\
\hline & & Mengalir 5 hari seminggu & 3 \\
\hline & & Mengalir 6 hari seminggu & 4 \\
\hline & & Mengali setiap hari & 5 \\
\hline & Frekuensi harian & Tidak pernah mengalir & 1 \\
\hline & & Waktu mengalir tidak tentu & 2 \\
\hline & & Tidak mengalir di jam sibuk & 3 \\
\hline & & Interupsi aliran $\leq 2 \mathrm{jam}$ & 4 \\
\hline & & Mengalir sepanjang hari & 5 \\
\hline & Deras air & Tidak mengalir & 1 \\
\hline & & Mati di jam sibuk/ deras setengah hari/ hanya deras di jam tertentu & 2 \\
\hline & & Lemah di jam sibuk/ aliran sedang & 3 \\
\hline & & Kurang deras $<2$ jam & 4 \\
\hline
\end{tabular}
seminggu, frekuensi air mengalir dalam satu hari, dan kederasan air), dan kualitas air. Analisis dilakukan dengan cara memberikan nilai atau skor di tiap variabel dengan nilai $1-5$. Bobot tiap variabel adalah sama. Nilai per variabel dijelaskan dalam tabel 2 .

Tabel 2. Tabel Variabel Dan Indikator Skoring 


\begin{tabular}{|c|c|c|c|}
\hline No & Variabel & Indikator & Nilai \\
\hline \multirow{5}{*}{3} & & Deras sepanjang hari & 5 \\
\hline & Kualitas & Berbau, berasa, dan berwarna & 1 \\
\hline & & Campuran salah satu dari berbau, berasa, dan berwarna & 2 \\
\hline & & Campuran dua dari berbau, berasa, dan berwarna & 3 \\
\hline & & Tidakberbau, tidak berasa, dan tidak berwarna & 5 \\
\hline
\end{tabular}

Adapun cara penilaian per variabel dilakukan dengan rumus berikut: $=\frac{\sum \text { nilai variabel }}{n}$ Khusus untuk penilaian variabel frekuensi dinilai dengan cara berikut;

$$
=\left(\frac{\sum \text { nilai frekuensi mingguan }}{n}+\frac{\sum \text { nilai frekuensi harian }}{n}+\frac{\sum \text { nilai deras }}{n}\right) / 3
$$

Kemudian, nilai akhir dirata-ratakan, sehingga didapatkan nilai range 1-5. Interpretasi nilai yang didapatkan adalah sebagai berikut:

Penilaian:

$1.00-1.9 \quad$ sangat buruk

$2-2.9 \quad$ buruk

3-3.9 cukup

$4-4.9 \quad$ baik

5 sangat baik/sempurna

\section{Hasil dan Pembahasan}

\subsection{Kualitas Ruang Hijau/Taman Kota}

Berdasarkan hasil analisis yang telah dilakukan, maka hasil analisa yang didapatkan menunjukkan bahwa terdapat perbedaan nilai yang cukup signifikan antara kedua sumber, yaitu PDAM dan artesis. Air bersumberkan PDAM bernilai 3.4 yang bermakna cukup sedangkan air bersumber artesis bernilai 4.6 yang bermakna baik. Keadaan demikian terjadi karena jauhnya sumber pipa utama yang tersambung ke rumah (2.6) dan bagaimana kualitas air yang diterima (3.2). Variabel jarak bagi pelanggan artesis jauh lebih tinggi nilainya (4.6) dibandingkan pelanggan PDAM (2.6) karena warga cenderung memilih berlangganan dengan sumber air yang lebih dekat pusat towernya ke rumah masing-masing.

Tabel 3. Hasil Analisis Aksesibilitas Air Berdasarkan Sumber air perpipaan

\begin{tabular}{lcccccccc}
\hline Sumber & Jarak & Fr Mingguan & Fr Harian & Fr Deras & $\sum$ Fr & Kualitas & $\sum$ Nilai & Ket \\
\hline PDAM & 2.6 & 4.6 & 4.2 & 3.8 & 4.2 & 3.2 & 3.4 & Cukup \\
Artesis & 4.6 & 5.0 & 4.7 & 4.4 & 4.7 & 4.4 & 4.6 & Baik \\
\hline
\end{tabular}

Penilaian:

$1.00-1.9 \quad$ sangat buruk

$2-2.9 \quad$ buruk

3-3.9 cukup

$4-4.9 \quad$ baik

5 sangat baik/sempurna

Ketika ditelisih lebih jauh berdasarkan wawancara kepada beberapa warga yang telah lama tinggal, walaupun kualitas air artesis terlihat jauh lebih baik (4.4) daripada kualitas air yang dirasakan oleh pelanggan PDAM (3.2), namun faktor kebiasaan menjadi hal penting dalam memilih bagaimana 
kualitas air sesungguhnya. Sebagai contoh, bagi warga yang pindah dari Tambak Lorok ke Kelurahan Kemijen merasa bahwa mayoritas air artesis di Tambak Lorok terasa asin dan tidak nyaman di tubuh serta berbau, sedangkan bagi masyarakat Tambak Lorok air yang mereka gunakan terasa enak, tidak berbau, dan nyaman di tubuh.

\subsection{Analisis Aksesibilitas Air Berdasarkan Kelompok masyarakat}

Analisis aksesibilitas air berdasarkan kelompok masyarakat yang dimaksud ialah dengan menggolongkan hasil analisis aksesibilitas ke dalam tiga golongan masyarakat menengah, yaitu mayarakat menengah ke bawah, menengah, dan menengah ke atas. Penggolongan ini bertujuan agar terlihat perbedaan akses di tiap golongan masyarakat. Analisis ini dilakukan tidak dengan memperhitungkan pemilihan air yang dijadikan sumber utama.

Tabel 4. Tabel Hasil Analisis Aksesibilitas Air Berdasarkan Kelompok masyarakat

\begin{tabular}{|c|c|c|c|c|c|c|c|c|}
\hline & Jarak & Fr Mingguan & Fr Harian & Fr Deras & $\sum \mathrm{Fr}$ & Kualitas & $\sum$ Nilai & Ket \\
\hline $\begin{array}{l}\text { Menengah } \\
\text { ke bawah }\end{array}$ & 3.4 & 4.7 & 4.4 & 3.9 & 4.4 & 3.6 & 3.8 & Cukup \\
\hline Menengah & 3.7 & 4.7 & 4.3 & 4.0 & 4.3 & 3.9 & 3.9 & Cukup \\
\hline $\begin{array}{l}\text { Menengah } \\
\text { ke atas }\end{array}$ & 3.8 & 5.0 & 4.7 & 4.4 & 4.7 & 4.0 & 4.2 & Baik \\
\hline $\begin{array}{l}\text { Penilaian: } \\
1.00-1.9 \\
2-2.9 \\
3-3.9 \\
4-4.9 \\
5\end{array}$ & $\begin{array}{l}\text { sangat } \\
\text { buruk } \\
\text { cukup } \\
\text { baik } \\
\text { sangat }\end{array}$ & $\begin{array}{l}\text { puruk } \\
\text { paik/sempurna }\end{array}$ & & & & & & \\
\hline
\end{tabular}

Berdasarkan hasil analisis, ada peningkatan nilai dari masyarakat menengah ke bawah yaitu 3,8 (cukup), masyarakat menengah 3.9 (cukup), dan yang tertinggi adalah masyarakat menengah ke atas 4.2 (baik). Walaupun ada perbedaan namun nilainya tidak terlalu signifikan. Hal ini menunjukkan bahwa akses di antara penduduk hampir merata, walaupun masyarakat menengah nilainya jauh lebih rendah (3.8) dibandingkan masyarakat menengah ke atas (4.2).

\subsection{Analisis Aksesibilitas Air Berdasarkan Sumber air perpipaan Dan Kelompok Masyarakat}

Analisis yang dimaksud ialah analisis aksesibilitas dengan turut mempertimbangkan sumber air perpipaan dan kelompok masyarakat. Maka, hasil yang didapatkan digolongkan ke dalam enam katagori. Analisis ini dilakukan agar terlihat bagaimana aksesibilitas air berdasarkan sumbernya dan bagaimana masyarakat menilai akses.

Hasil yang didapatkan menunjukkan hasil yang tidak jauh berbeda dengan hasil penggolongan aksesibilitas hanya dengan sumber airnya, dimana masyarakat yang berlangganan PDAM cenderung memiliki nilai yang cukup sedangkan pelanggan artesis memiliki nilai baik. Perbedaan nilai antara masyarakat menengah ke bawah, menengah, dan menengah ke atas tidak terlalu signifikan namun semakin meningkat, kecuali yang dialami oleh pmasyarakat menengah yang berlangganan artesis.

Variabel yang menarik adalah bahwa berbeda dengan kelompok masyarakat menengah dan menengah ke bawah yang berlangganan PDAM yang cendeerung menilai bahwa kualitas air yang 
didapatkan berkisar pada nilai 3 (3.1 dan 3.4), masyarakat menengah ke atas menilai bahwa kualitas air PDAM yang diperoleh berada pada nilai 4.4 (baik).

Tabel 5. Tabel Hasil Analisis Aksesibilitas Air Berdasarkan Sumber air perpipaan Dan Kelompok Masyarakat

\begin{tabular}{|c|c|c|c|c|c|c|c|c|}
\hline $\begin{array}{l}\text { Kelompok } \\
\text { Masyarakat }\end{array}$ & Jarak & Fr Mingguan & Fr Harian & Fr Deras & $\sum \mathbf{F r}$ & Kualitas & $\sum$ Nilai & Ket \\
\hline \multicolumn{9}{|c|}{ Menengah ke bawah } \\
\hline PDAM & 2.7 & 4.6 & 4.2 & 3.6 & 4.1 & 3.1 & 3.4 & Cukup \\
\hline Artesis & 4.5 & 5.0 & 4.7 & 4.5 & 4.7 & 4.4 & 4.5 & Baik \\
\hline \multicolumn{9}{|l|}{ Menengah } \\
\hline PDAM & 2.6 & 4.3 & 4.1 & 3.9 & 4.1 & 3.4 & 3.5 & Cukup \\
\hline Artesis & 4.8 & 5.0 & 4.5 & 4.1 & 4.5 & 4.4 & 4.4 & Baik \\
\hline \multicolumn{9}{|c|}{ Menengah ke atas } \\
\hline PDAM & 2.6 & 5.0 & 4.5 & 4.1 & 4.5 & 4.4 & 3.9 & Cukup \\
\hline Artesis & 4.6 & 5.0 & 4.9 & 4.6 & 4.8 & 4.5 & 4.7 & Baik \\
\hline $\begin{array}{l}\text { Penilaian: } \\
1.00-1.9 \\
2-2.9 \\
3-3.9 \\
4-4.9 \\
5\end{array}$ & $\begin{array}{l}\text { sangat } \\
\text { buruk } \\
\text { cukup } \\
\text { baik } \\
\text { sangat }\end{array}$ & aik/sempurna & & & & & & \\
\hline
\end{tabular}

\subsection{Analisis Aksesibilitas Air Secara Keseluruhan}

Setelah dilakukan analis-analisa di atas, maka perlu dilakukan analisa berapa sesungguhnya nilai aksesibilitas yang dimiliki penduduk, Hasil yang didapatkan menunjukkan bahwa aksesibilitas di wilayah studi yang bila digenealisir adalah aksesibilitas penduduk menengah di Kawasan padat penduduk adalah 3.9 atau cukup. Namun, nilai ini tidak bisa diterima begitu saja tanpa mempertimbangkan bahwa akses yang layak adalah akses perpipaan dan yang diatur oleh negara, yaitu dari PDAM. Dari keseluruhan variabel yang ada, nilai cukup berasal dari variabel jarak (3.6) dan kualitas (3.8), sedangkan variabel lainnya mendapatkan nilai baik. Hasil analisis dijelaskan pada Tabel 6.

Tabel 6. Tabel Hasil Analisis Aksesibilitas Air Di Wilayah Studi

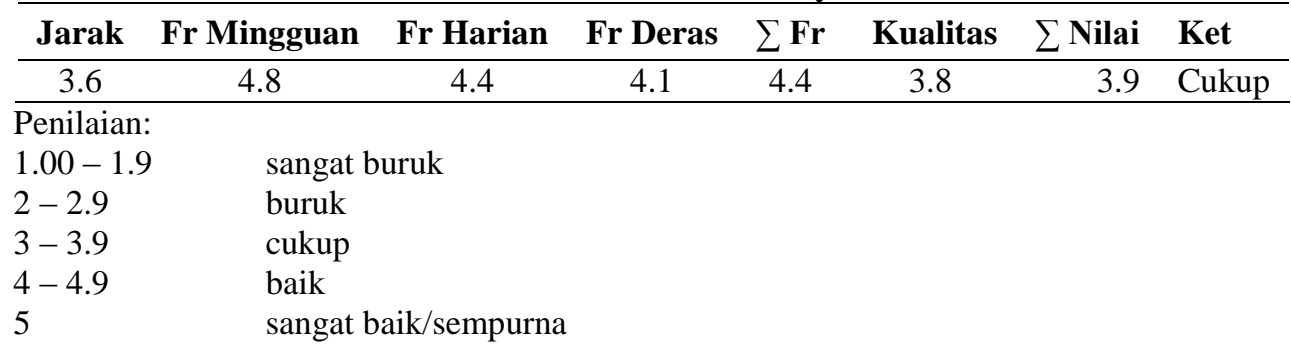

Berdasarkan hasil yang telah dianalisa sebelumnya dan disesuaikan dengan hasil keseluruhan, maka dapat disimpulkan bahwa masyarakat menengah ke bawah dan masyarakat menengah yang menggunakan PDAM mempunyai akses di bawah nilai aksesibilitas secara keseluruhan. Bila mengingat bahwa sumber artesis adalah rentan karena pengambilan air telah dilarang dalam 
Rencana Tata Ruang Wilayah, maka walaupun nilai aksesibilitas air artesis jauh lebih baik daripada PDAM tetap lebih rentan. Keadaan ini menunjukkan bahwa masyarakat menengah hingga menengah ke bawah cenderung lebih rentan terhadap akses air bersih.

\section{Kesimpulan}

Berdasarkan hasil analisis, maka didapatkan hasil bahwa secara keseluruhan, akses pelayanan air di kawasan padat penduduk di Kota Semarang adalah cukup dan bahkan hampir ke nilai baik. Akan tetapi bila dilihat berdasarkan penyedia jasa, maka terlihat jelas bahwa sumber air yang disediakan oleh penyedia air tanah jauh lebih baik daripada sumber air yang disediakan oleh pemerintah. Padahal, seharusnya sumber air yang disediakan pemerintah adalah yang terbaik. Seluruh nilai variabel memberikan porsi yang signifikan, namun gap nilai tertinggi berdasarkan hasil penelitian adalah variabel jarak dan kualitas. Perbedaan akses air bersih antar sumber air perpipaan dan kelompok masyarakat memberikan penekanan untuk hasil akses pelayanan berdasarkan penyedia sumber air, yaitu bahwa penyedia sumber air tanah mampu memberikan akses yang lebih baik daripada akses yang diberikan oleh penyedia sumber air pemerintah.

Perbedaan akses air bersih antar kelompok masyarakat yaitu masyarakat menengah ke bawah, menengah, dan menengah ke atas tidaklah signifikan. Namun terdapat gap yang terlihat jelas antara kelompok masyarakat menengah ke bawah dan menengah ke atas, di mana hasil akses air bagi kelompok masyarakat menengah ke bawah adalah cukup sedangkan hasil akses air bagi kelompok masyarakat menengah ke atas adalah baik. Keseluruhan nilai variabel memberikan andil yang hampir sama, yang dapat diartikan bahwa masyarakat menengah ke atas secara jarak, frekuensi, maupun kualitas mendapatkan akses yang jauh lebih layak dibandingkan dengan masyarakat menengah ke bawah.

Penyediaan air bersih adalah vital bagi kehidupan masyarakat, tak terkecuali di kawasan padat perkotaan. Di sisi lain, masyarakat menengah ke bawah sebagai pihak yang paling rentan memang memiliki akses yang lebih rendah daripada masyarakat menengah dan lebih jauh lagi bila dibandingkan dengan masyarakat menengah ke atas. Maka, pemerintah selain mempunyai pekerjaan rumah yang besar demi bisa setidaknya mengimbangi pelayanan yang diberikan oleh penyedia sumber air tanah, juga punya pekerjaan besar untuk mampu memberikan layanan yang prima tidak hanya bagi kelompok masyarakat menengah ke atas, melainkan hingga ke kelompok masyarakat menengah ke bawah.

\section{Daftar Pustaka}

Allen, A., \& Dávila, J. D. (2006). The peri-urban water poor : citizens or consumers ?, 18(2), 333351.

Howard, G., \& Bartram, J. (2003). Domestic Water Quantity, Service Level and Health. World Health Organization. Geneva: WHO Press.

Indonesia. Peraturan Mentri Kesehatan Nomor: 416 / MEN . KES / PER / IX / 1990 Tentang Syarat-syarat Dan Pengawasan Kualitas Air (1990).

Suhartono, E., Suripin, \& Purwanto. (2013). Kondisi Intrusi Air Laut Terhadap Air Tanah Pada Akuifer di Kota Semarang. Prosiding Seminar Nasional Pengelolaan Sumberdaya Alam Dan Lingkungan, (2011), 396-401.

Watkins, K. (2006). Human Development Report 2006 - Beyond scarcity: Power, poverty and the global water crisis. Journal of Government Information (Vol. 28). 
WHO. (2007). World Health Organization's "10 Facts About Water Scarcity." Retrieved November 3, 2017, from https://www.wateronline.com/doc/world-health-organizations-10facts-about-wat-0001?VNETCOOKIE=NO

Widyonarso, E. S., \& Yuliastuti, N. (2014). Tingkat Aksesibilitas Fasilitas Sosial Berdasarkan Konsep Unit Lingkungan Di Perumnas Banyumanik Kota Semarang Accessibility Level Of Social Facilities Based On Neighborhood Unit Concept In Perumnas Banyumanik Semarang City. Ruang, 2(4), 351-360. 